\title{
Safety of general anaesthesia and surgery in acute hepatic porphyria
}

\author{
S B Dover, L Plenderleith, M R Moore, K E L McColl
}

\begin{abstract}
Patients with acute hepatic porphyria are denied essential operations because of concern that general anaesthesia and surgery will precipitate a life threatening porphyric crisis. This study assessed the safety of surgery under general anaesthesia in these patients. A combined prospective and retrospective case note study, with a biochemical study, was conducted in 25 patients with acute hepatic porphyria undergoing 38 surgical operations. Clinical outcome measures were survival and occurrence of porphyric crisis after surgery. The biochemical activity of porphyria was assessed by measurement of the perioperative 24 hour excretion of the haem precursors $\delta$ aminolaevulinic acid (ALA) and porphobilinogen (PBG). There were no deaths or crises after 29 operations in 19 patients who were known to have porphyria before their surgery, and therefore given only appropriate drugs. These operations include such major procedures as mitral valve replacement, hip replacement, coronary artery grafting, cholecystectomies, and renal transplantation. In eight of these patients the urinary excretion of ALA and PBG were studied, and showed no sustained postoperative increase. Nine operations were performed in eight patients before the diagnosis of porphyria was known and who thus received routine anaesthetic agents. Seven of these patients developed a postoperative porphyric crisis. Two of them died. It is concluded therefore that even the most major surgery can be undertaken safely in patients with porphyria. The risk is for undiagnosed cases.
\end{abstract}

(Gut 1994; 35: 1112-1115)

University Department of Medicine and

Therapeutics

$S$ B Dover

M R Moore

KE L McColl

and Department of Anaesthesia, Western Infirmary, Glasgow L Plenderleith

Correspondence to: Dr S Dover, Department of Gastroenterology, Level 8, Gartnavel General Hospital, 1053, Great Western Road, Glasgow G12 0YN.

Accepted for publication 23 November 1993
The acute hepatic porphyrias are a group of inherited metabolic disorders of the haem biosynthetic pathway. ${ }^{1}$ The cardinal feature of these diseases is the development of acute crises, which have an appreciable mortality. Episodes are characterised by severe abdominal pain, paralysis, seizures, hypertension, and tachycardia. During the porphyric episode, there is overproduction and increased urinary excretion of the haem precursors formed proximal to the metabolic block - that is, $\delta$ amino laevulinic acid (ALA) and porphobilinogen (PBG). The activity of the porphyria can be assessed by measuring their 24 hour urinary excretion.
Because the porphyrias are a group of metabolic liver diseases characterised by episodic abdominal pain, many of these patients and their families are under the care of gastroenterologists, hepatologists or surgeons. Because they are rare diseases, few such physicians have wide experience of their treatment, and therefore guidelines from specialist centres are particularly important.

Acute porphyric crises can be precipitated by a variety of factors including certain drugs, starvation, infection, and metabolic stress. ${ }^{2}$ These factors come together at the time of a surgical operation. Patients with acute hepatic porphyria may thus be denied surgical treatment for coexisting diseases, because of fear of precipitating a life threatening porphyric crisis.

We have been aware of patients with porphyria undergoing major surgery without complication, of others having a crisis after minor surgery, and also of surgeons denying essential surgery to patients because of porphyria. This has prompted us to review the surgical experiences of our patients to try and identify risk factors and suggest guidelines for safe anaesthesia and surgery in acute hepatic porphyria.

\section{Methods}

This was a combined retrospective and prospective study. For the retrospective part, case records were reviewed and patients interviewed to identify previous surgical operations before or after the diagnosis of porphyria was made. Attempts were then made to obtain the hospital records including operation and anaesthetic notes and details of any postoperative problem.

For the prospective part we studied eight known porphyric patients undergoing a variety of operations. In five of these cases it was possible to assess the activity of their porphyria perioperatively by monitoring the 24 hour urinary excretion of porphyrin precursors. Urinary ALA and PBG concentrations were measured by spectrophotometric assay. ${ }^{3}$

\section{Results}

Altogether 38 surgical operations were identified among 25 patients (18 women). Thirty of these operations were performed in 20 patients with acute intermittent porphyria, seven operations in four patients with variegate porphyria, and one in a patient with hereditary coproporphyria. Eighteen operations in 11 patients were done in our own hospital, and 20 operations in 15 patients elsewhere. Nine 
TABLE I Operations and their outcome in patients known to have porphyria

\begin{tabular}{lllll}
\hline Patient & Sex & Porphyria & Age & Operation \\
\hline 1 & F & VP & 62 & Cholecystectomy \\
2 & M & AIP & 37 & Vagotomy, cholecystectomy, and splenectomy \\
3 & M & AIP & 45 & Total hip replacement \\
4 & F & VP & 49 & Renal impairment \\
& & & 42 & EUA+D and C \\
5 & F & AIP & 46 & Cotal abdominal hysterectomy \\
6 & F & AIP & 52 & Cholecystectomy \\
7 & F & AIP & 55 & Evacuation of uterus \\
& & & 64 & Mitral valve replacement \\
8 & F & AIP & 48 & Caesium implant \\
9 & F & AIP & 54 & Renal transplant \\
10 & F & AIP & 47 & Total abdominal hysterectomy \\
11 & M & AIP & 5 & Dental clearance \\
12 & F & VP & 74 & Laparotomy, drainage of sub-phrenic and retroperitoneal \\
& & & & abscess \\
13 & F & AIP & 34 & Toe fusion \\
14 & F & AIP & 62 & Mastectomy and axillary clearance \\
15 & F & AIP & 51 & Coronary artery vein graft \\
16 & M & AIP & 46 & Vagotomy and pyloroplasty \\
17 & F & AIP & 49 & Insertion of Tenckoff catheter \\
& & & 49 & Removal and replacement of Tenckoff catheter \\
& & & 50 & Renal transplant \\
& & & 52 & Laparotomy and Hartman's procedure \\
& & & 52 & Reversal of colostomy \\
18 & F & AIP & 53 & Transplant nephrectomy \\
25 & M & HCP & 24 & D and C \\
& & 49 & D and C, laparoscopy and tubal ligation \\
& & & & Spinal laminectomy \\
\hline & & &
\end{tabular}

$\mathrm{AIP}=$ acute intermittent porphyria, $\mathrm{VP}=$ variegate porphyria, $\mathrm{HCP}=$ hereditary coproporphyria, EUA = examination under anaesthesia, $\mathrm{D}$ and $\mathrm{C}=$ dilatation and curettage.

$\star$ Perioperative porphyrin biochemistry available (see Figure)

operations were performed in eight patients before the diagnosis of porphyria was made, and 29 operations in 19 known porphyric patients. There are biochemical data concerning one operation each in eight patients.

SURGERY IN PATIENTS KNOWN TO HAVE ACUTE PORPHYRIA

Twenty nine operations were performed on 19 patients known, before the time of surgery, to have acute porphyria (15 acute intermittent porphyria, 3 variegate porphyria, 1 hereditary coproporphyria). There were 14 women and five men, mean age at time of operation 46.5 years (range 5 to 74 ). The operations ranged from minor procedures to open heart surgery (Table I). In all of these patients anaesthetics and perioperative drugs believed to be unsafe in porphyria were avoided. Table II shows details of the anaesthetics and other drugs given to these patients.

None of the 29 operations in these 19 patients recognised as having porphyria preoperatively precipitated a clinical attack of porphyria. There were minor complications in four (an antibiotic associated rash, troublesome constipation, continuing abdominal discomfort, and a ketamine nightmare). The only serious complication was a small stroke on the fourth day after a renal transplant. The only mechanism by which this could be attributable to porphyria would be as a feature of a hypertensive crisis, which it was not.

The Figure shows the PBG and ALA excretions in the five patients in whom it was monitered perioperatively. The five operations were hip replacement (patient 2), cholecystectomy (patients 4 and 5), evacuation of uterus (patient 6), and femoropopliteal bypass grafting (patient 7).

Only patient 2 had a significantly increased ALA excretion - more than four times the upper limit of normal preoperatively; it doubled on the third postoperative day, but had returned to preoperative values by the seventh postoperative day. The other three patients for whom preoperative values are available show no rise in ALA excretion after surgery. Patient 7 , for whom there are no preoperative data (because it was an emergency operation), did show a postoperative rise, but not to values associated with a porphyric crisis.

The PBG excretion was normal in three of the patients preoperatively. In two of these it did not change postoperatively, but in the other one it increased between the second and third postoperative days, but had returned to within the normal range by day 4 . In one patient the PBG value was increased preoperatively; it nearly doubled on the third and fourth postoperative days, but was back to preoperative values by day 7 . The patient for whom there were no preoperative data also showed a transient rise between days 2 and 4.

None of the transient rises in ALA or PBG was associated with clinical evidence of disease activity or crisis.

Less complete biochemical data are available for three further patients. Patient 1 had normal values of ALA and PBG on the second postoperative day. In patient 3 urine analysis was not possible preoperatively as he was receiving haemodialysis. Two days after his renal transplant, however, urinary excretion of ALA and PBG were normal. Because of her radioactive implant, patient 8 could not have urine collected on the day of operation or first day afterwards, but a preoperative collection, and one on the second postoperative day were both normal. These data do not point to perioperative activation of porphyria in any of the three cases.

TABLE II Anaesthetic and other drugs used in the patients known to have porphyria

\begin{tabular}{|c|c|c|c|c|c|c|c|c|c|}
\hline Premedication & & Induction & & Paralysis & & Maintenance & & Reversal & \\
\hline $\begin{array}{l}\text { Temazepam } \\
\text { Cyclizine } \\
\text { Atropine } \\
\text { Morphine } \\
\text { Lorazepam } \\
\text { Chlorpromazine } \\
\text { Myoscine } \\
\text { Omnopon } \\
\text { Fentanyl } \\
\text { Droperidone }\end{array}$ & $\begin{array}{l}4 \\
4 \\
4 \\
3 \\
2 \\
2 \\
1 \\
1 \\
1 \\
1\end{array}$ & $\begin{array}{l}\text { Propofol } \\
\text { 'Inhalation' } \\
\text { Halothane } \\
\text { Ketamine } \\
\text { Nitrous oxide } \\
\text { Etomidate } \\
\text { Fentanyl } \\
\text { Diazemuls } \\
\text { Alfentanyl } \\
\text { Midazolam }\end{array}$ & $\begin{array}{r}15 \\
3 \\
2 \\
2 \\
1 \\
2 \\
2 \\
1 \\
1 \\
1\end{array}$ & $\begin{array}{l}\text { Suxamethonium } \\
\text { D-turbocurapine } \\
\text { Atracurium } \\
\text { Neostigmine } \\
\text { Vancuronium }\end{array}$ & $\begin{array}{r}10 \\
8 \\
5 \\
4 \\
1\end{array}$ & $\begin{array}{l}\text { Nitrous oxide } \\
\text { Propofol infusion } \\
\text { Morphine } \\
\text { Ethrane } \\
\text { Isofluorane } \\
\text { Pentazocine } \\
\text { Fentanyl } \\
\text { Alfentanyl } \\
\text { Pethidine } \\
\text { Halothane } \\
\text { Ether } \\
\text { Ketamine } \\
\text { Diazemuls }\end{array}$ & $\begin{array}{r}18 \\
8 \\
5 \\
3 \\
6 \\
2 \\
4 \\
1 \\
1 \\
1 \\
1 \\
1 \\
1\end{array}$ & $\begin{array}{l}\text { Neostigmine } \\
\text { Atropine }\end{array}$ & 4 \\
\hline
\end{tabular}


TABLE III Operations and their outcome in patients with undiagnosed porphyria

\begin{tabular}{|c|c|c|c|c|c|}
\hline Patient & $\operatorname{Sex}$ & Porphyrin & Age & Operation & Outcome \\
\hline 4 & $\mathrm{~F}$ & VP & 21 & Appendicectomy ${ }^{\star}$ & $\begin{array}{l}\text { Post operation crisis. Abdominal pain and paralysis. } \\
\text { Diagnosed and survived. Persisting parapesis }\end{array}$ \\
\hline 9 & F & AIP & 33 & Ovarian cystectomy ${ }^{\star}$ & $\begin{array}{l}\text { Crisis after operation. Worsening of pain and severe } \\
\text { hypertension. Recovered }\end{array}$ \\
\hline 19 & $\mathrm{~F}$ & AIP & 32 & $\begin{array}{l}\text { Removal of transitional cell papilloma } \\
\text { on nose and plastic reconstruction }\end{array}$ & $\begin{array}{l}\text { Post operation crisis. Abdominal pain, hyponatraemia } \\
\text { seizures. Diagnosed. Recovered }\end{array}$ \\
\hline 20 & F & VP & 52 & Emergency cholecystectomy ${ }^{\star}$ & $\begin{array}{l}\text { Died of porphyric crisis despite diagnosis and haem } \\
\text { therapy }\end{array}$ \\
\hline 21 & M & AIP & 40 & Investigative laparotomy ${ }^{\star}$ & $\begin{array}{l}\text { Developed paralysis and pain. Died day } 4 \text {. Undiagnosed } \\
\text { until grand-daughter developed disease }\end{array}$ \\
\hline 22 & F & AIP & 19 & $\begin{array}{l}\text { Laparotomy and hysteropexy } \\
\text { Abdominal hysterectomy }\end{array}$ & $\begin{array}{l}\text { Uncomplicated recovery } \\
\text { Uncomplicated recovery. Diagnosis made when daugh- } \\
\text { ter developed disease }\end{array}$ \\
\hline 23 & F & AIP & 7 & Appendicectomy ${ }^{\star}$ & $\begin{array}{l}\text { Post operative worsening of pain. Seizures. Crisis diag- } \\
\text { nosed. Anti-convulsants withdrawn. Survived }\end{array}$ \\
\hline 24 & F & AIP & 19 & Appendicectomy ${ }^{\star}$ & $\begin{array}{l}\text { Post operative psychosis, progressed to seizures and } \\
\text { paralysis before diagnosis. Incomplete recovery. } \\
\text { Appendix normal }\end{array}$ \\
\hline
\end{tabular}

${ }^{\star}$ Operation (probably) performed for symptoms of unrecognised porphyric attack. Abbreviations as in Table I.

OPERATIONS UNDERTAKEN BEFORE THE DIAGNOSIS OF PORPHYRIA WAS KNOWN

We have identified nine operations that were performed in eight patients (seven women), before the diagnosis of porphyria was recognised (Table III). Six patients had acute intermittent porphyria, and two variegate porphyria, with a mean age at time of operation of 30 years (range 7-52). There were only two uncomplicated recoveries with seven crises resulting in two deaths.

Abdominal pain, usually similar to that for which the operation had been performed, was a feature in all seven postoperative crises. Three patients had seizures, one associated with a serum sodium of $112 \mathrm{mmol} / \mathrm{l}$ resulting from the syndrome of inappropriate antidiuretic hormone secretion. Four had considerable neuropathy, one hypertension, and one a psychosis.

\section{Discussion}

This study shows that surgery can be undertaken safely in patients with acute porphyria, provided that contraindicated drugs and anaesthetic agents are avoided. It also emphasises the danger of surgery in patients not recognised to have porphyria and who therefore receive contraindicated drugs.

None of the 29 operations performed in patients known to have porphyria resulted in clinical consequences attributable to porphyria. In addition, eight patients already known to have porphyria showed no evidence
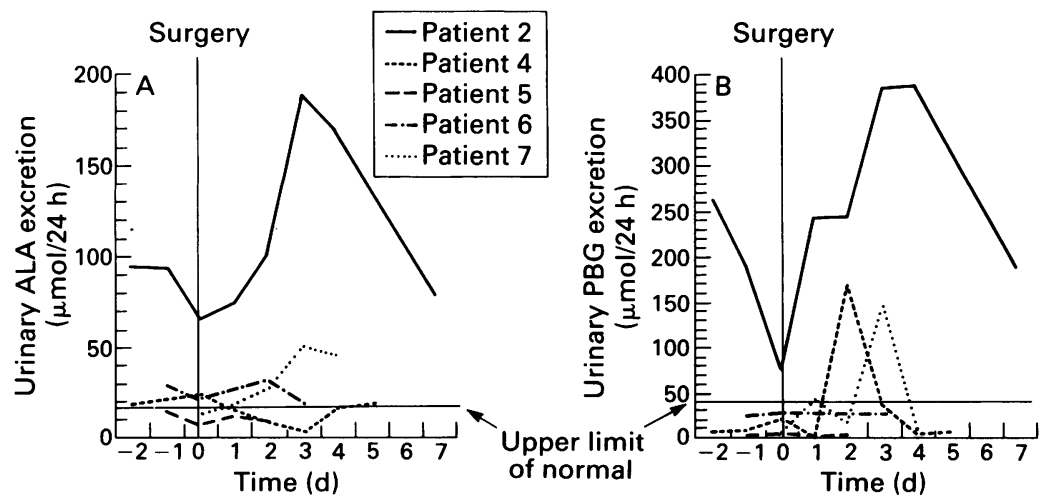

(A) Perioperative 24 hour urinary excretion of $\delta$ aminolaevulinic acid ( $A L A)$;

(B) perioperative 24 hour urinary excretion of porphobilinogen (PBG). of a sustained rise in markers of disease activity over preoperative values. The transient rises in ALA or PBG that were seen in three patients were not associated with clinical evidence of disease activity. They may represent subclinical disease activity, associated with some aspect of the operation, for example, drugs, starvation, stress, etc. ${ }^{4}$ Alternatively these rises may not truly be reflecting disease activity, perhaps resulting from increased haem synthesis due to blood loss, or a consequence of blood transfusion. ${ }^{5}$

This study also confirms that provided the necessary precautions are taken patients with porphyria can safely undergo even the most major surgery, for example heart valve replacement, coronary artery grafting, and hip replacement. ${ }^{67}$

Propofol was the most commonly used intravenous anaesthetic agent, confirming a previous prospective study of its safety in varieagate porphyria. ${ }^{8}$ There is, however, a report of biochemical activation of porphyria after propofol administration. ${ }^{9}$ The choice of drugs and anaesthetics used in the patients known to have porphyria was based on clinical experience ${ }^{10-12}$ and animal studies. ${ }^{13}$ This type of information has been compiled for clinical use, ${ }^{14}$ and its value is supported by the favourable outcome of the patients in this study.

In addition to the correct choice of anaesthetic and drugs, it is important to avoid starvation ${ }^{15}$ in the perioperative period, as this can also trigger an attack; patients should be given intravenous glucose ${ }^{16}$ perioperatively, until able to resume an adequate diet. Because of the danger of hyponatraemia in acute porphyria (caused by the syndrome of inappropriate secretion of antidiuretic hormone - see patient 19's first operation) the serum sodium should be monitored.

In contrast with the favourable outcome in the patients known to have an acute porphyria at the time of surgery, the outcome in those in whom the diagnosis was not known was extremely poor. with seven crises resulting in two deaths, and only two uncomplicated recoveries. The information about the operations performed, and the anaesthetic agents used in these patients is much less complete because at the time they were of no particular 
interest, and in some cases records have been destroyed or become unavailable. It can be assumed, however, that these patients received standard anaesthetics, most of which are highly porphyrinogenic. ${ }^{13} 14$ This probably explains the poor outcome.

Moreover, in retrospect, it seems probable that seven of these nine operations were undertaken for symptoms of porphyria. These operations, where the diagnosis was unknown and the disease was active, were particularly hazardous; with two fatal and two non-fatal crises, and only one patient recovering without complication, twice. This is similar to previous reported experience, ${ }^{17}$ where all seven patients given thiopental to induce anaesthesia during an acute symptomatic episode of porphyria worsened biochemically and clinically.

Because acute porphyria is an uncommon disease, which can mimic other conditions, it is likely to have caused other undiagnosed postoperative deaths and morbidity. Patients with porphyria need appropriate treatment when they develop a true abdominal surgical emergency, though this can be difficult to diagnose. 18

Three patients had operations before the diagnosis was made, and further surgery afterwards. The prediagnosis operations were minor (two appendicectomies and one ovarian cystectomy) compared with the postdiagnosis operations (total hysterectomy, cholecystectomy, and renal transplant). Nevertheless, these patients each had a porphyric crisis as a result of the anaesthetic and minor operation undertaken before diagnosis, but had no complications of porphyria after operations when they were known to be porphyric, and thus received only safe agents.

The problem of patients being denied surgery because of porphyria is exemplified by patient 14 . Her original surgeon and his anaesthetist would not undertake lumpectomy for a small breast tumour. She could not be given endocrine treatment because of its porphyrinogenicity. ${ }^{14}$ Eighteen months later she re-presented with extensive local disease requiring mastectomy and axillary clearance for cosmesis and local control. She later died of metastatic disease. This outcome may have been avoided by earlier and less mutilating surgery.

In conclusion, this study shows that even major and repeated surgery can be performed without complication in patients with acute hepatic porphyria. Safety depends upon a knowledge of the diagnosis and which anaesthetic agents are safe. The risk is for undiagnosed cases, and continued awareness of the features of this disease is required to prevent crises and deaths.

1 Goldberg A, Moore MR, McColl KEL, Brodie MJ. Porphyrin metabolism and the porphyrias. In: Wetherall DJ, Ledingham JGG, Warrell DA, eds. Oxford textbook of medicine. 2nd Ed. Oxford: Oxford University Press, 1987.
med

2 McColl KEL, Moore MR. The acute porphyrias - an example of pharmacogenetic disease. Scott Med $\mathcal{F} 1980$; 26: $32-40$.

Mauzerall D, Granick S. The occurrence and determination of 5-aminolaevulinic acid and porphobilinogen in urine f Biol Chem 1956; 219: 435-46.

4 Herrick AL, McColl KEL, Moore MR, Cook A, Goldberg A. Controlled trial of haem arginate in acute hepatic porphyria. Lancet 1989; i: 1295-7.

5 Moore MR, McColl KEL, Rimmington C, Goldberg A Porphyrins in diseases other than the porphyrias. In Disorders of porphyrin metabolism. New York: Plenum Medical, 1987.

6 Campos JH, Stein DK, Michel MK, Moyers JR. Anesthesia for aortic valve replacement in a patient with acute intermittent porphyria. $\mathcal{F}$ Cardiothorac Vasc Anesth 1991; 5: 258-61.

7 Shipton EA, Roelofse JA. Anaesthesia in a patient with variegate porphyria undergoing coronary bypass surgery. $S$ Afr Med f 1984; 65: 53-4.

8 Meissner PN, Harrison GG, Hift RJ. Propofol as an iv anaesthetic induction agent in variegate porphyria. $B r \mathcal{F}$ Anaesth 1991; 66: 60-5.

9 Weir PM, Hodkinson BP. Is propofol a safe agent in porphyria? Anaesthesia 1988; 43: 1022-3.

10 Mitterschiffthaler G, Theiner A, Hetzel H, Fuith LC. Safe use of propofol in a patient with acute intermittent porphyria. Br $¥$ Anaesth 1988; 60: 109-11.

11 Famewo CE. Induction of anaesthesia with etomidate in a patient with acute intermittent porphyria. Can Anaesth Soc f 1985; 32: 171-3.

12 Capouet V, Dernovoi B, Azagra JS. Induction of anaesthesia with ketamine during an acute crisis of hereditary coproporphyria. Can $\mathcal{F}$ Anaesth 1987; 34: 388-90.

13 Parikh RK, Moore MR. Effect of certain anaesthetic agents on the activity of rat hepatic $\kappa$-aminolaevulinate synthase. Br $\mathcal{F}$ Anaesth 1978; 50: 1099-102.

14 Moore MR, McColl KEL. Porphyria drug lists. Cumbernauld: Hunterprint, 1991.

15 Moore MR, McColl KEL, Rimmington C, Goldberg A. The acute porphyrias - precipitating factors. In: Disorders of porphyrin metabolism. New York: Plenum Medical, 1987.

16 Brodie MJ, Moore MR, Thompson GG, Goldberg A. The treatment of acute intermittent porphyria with laevulose. treatment of acute intermittent porphy
Clin Sci Mol Med 1977; 53: 365-71.

17 Mustajoki P, Heinonen J. General anesthesia in inducible porphyrias. Anesthesiology 1980; 53: 15-20.

18 Schmidt GA, Corbridge TC. Appendicitis masquerading as acute porphyria. Crit Care Med 1991; 19: 443-5. 